\title{
Fragile X Premutation: Medications, Therapy and Lifestyle Advice
}

\author{
Deepika Kour Sodhi ${ }^{1}$ \\ Randi Hagerman (D) ${ }^{1,2}$ \\ 'The MIND Institute, University of \\ California Davis Health, Sacramento, CA, \\ USA; ${ }^{2}$ Department of Pediatrics, \\ University of California Davis Health, \\ Sacramento, CA, USA
}

\begin{abstract}
The fragile $X$ premutation is characterized by 55-200 CGG repeats in the 5 untranslated region of FMR1, whereas full fragile X mutation has greater than 200 repeats and full methylation, which manifests as fragile $\mathrm{X}$ syndrome (FXS). The premutation spectrum of clinical involvement includes fragile X-associated tremor/ataxia syndrome (FXTAS), fragile X-associated primary ovarian insufficiency (FXPOI), and fragile $\mathrm{X}$-associated neuropsychiatric disorders (FXAND). In addition, premutation carriers also suffer from various other health problems such as endocrine abnormalities and autoimmune problems. In this paper, we have discussed different health issues faced by the carriers and interventions including medications, therapy and lifestyle changes that could improve their health.
\end{abstract}

Keywords: FMR1, fragile $\mathrm{X}$ mental retardation 1, fragile $\mathrm{X}$ premutation, medication, antioxidants, exercise, FXTAS, FXPOI, FXAND

\section{Introduction}

Fragile X premutation (PM) carriers have 55-200 CGG repeats in the 5' untranslated region of the fragile-X mental retardation 1 (FMR1) gene. The premutation occurs in approximately 1 in 130-250 women and 1 in 250-800 men in the general population. ${ }^{1-3}$ A woman with the premutation has a high risk of passing on a full mutation $(>200$ repeats) to her children and the full mutation causes fragile $\mathrm{X}$ syndrome (FXS), the most common inherited cause of intellectual disabilities (ID) and autism. Although most individuals with the premutation do not have ID, they can have a variety of health problems associated with RNA toxicity because there are enhanced levels of FMRI mRNA in premutation carriers. The higher the CGG repeat number, the higher the level of mRNA. ${ }^{4}$ The elevated mRNA levels lead to calcium dysregulation, mitochondrial dysfunction, sequestration of proteins important for neuronal function, oxidative stress, and enhanced neuronal cell death. $^{5}$ The three most researched clinical disorders associated with premutation are fragile X-associated tremor/ataxia syndrome (FXTAS), fragile X-associated primary ovarian insufficiency (FXPOI), and fragile X-associated neuropsychiatric disorders (FXAND). Recently, the term Fragile X Premutation-associated Conditions (FXPAC) has been proposed by the European Fragile $\mathrm{X}$ Network (EFXN) to include all the problems related to fragile $\mathrm{X}$ premutation. ${ }^{6}$ Additional medical conditions associated with the premutation include connective tissue problems, endocrine dysfunction particularly thyroid problems, immune mediated disorders such as fibromyalgia, multiple sclerosis, autoimmune thyroid disease,
Correspondence: Randi Hagerman UC Davis MIND Institute, 2825 50th Street, Room 2221, Sacramento, CA 95817, USA

Tel + I 916-703-0247

Email rjhagerman@ucdavis.edu

Deepika Kour Sodhi

UC Davis MIND Institute, 2825 50th

Street, Room 222I, Sacramento, CA 95817, USA

Email deepikakour219@gmail.com 
and other health problems including hypertension, migraine, restless legs syndrome, insomnia and sleep apnea. $^{3,7}$

The major cause behind the clinical signs and symptoms seen in the premutation carriers is elevated mRNA and at the upper end of the premutation (>120 CGG repeats), the level of the FMR1 protein (FMRP) can be reduced significantly. ${ }^{8}$ Though FMRP is present in all our cells, it is most abundant in the brain. On the molecular level, FMRP binds with transcripts and exerts its various effects by regulating RNA synthesis, mRNA transport, and mRNA translation for hundreds of genes and by binding with certain proteins such as ion channels to control their function. A better understanding of this protein and its downstream effects when deficient would help us in creating advanced and targeted treatment options for both those with FXS and in carriers. ${ }^{9}$

Although there is no cure for premutation disorders there are treatments that can help to alleviate many of the symptoms and lifestyle changes that can help to avoid some of the long term problems. This paper is an update on various therapeutic approaches used in the treatment of premutation disorders.

\section{FXAND, FXPOI and FXTAS: Clinical Background}

FXAND is an umbrella term used to cover various neuropsychiatric problems experienced by the premutation carriers. $^{10,11}$ The psychiatric problems covered under FXAND include anxiety, depression, attention deficit hyperactivity disorder (ADHD), substance abuse, chronic fatigue, chronic pain, sleep problems, and behavioral changes, among others. ${ }^{10-12}$ The two frequently encountered psychiatric disorders in the premutation carriers are depression and anxiety. The structured clinical interview for diagnosis (SCID) using Diagnostic and Statistical Manual of Mental Disorders, fourth edition, text revision (DSM-IV-TR) criteria showed significantly higher lifetime risk of mood and anxiety disorders in the fragile $\mathrm{X}$ premutation carriers as compared to the general population. ${ }^{13}$ Seritan et al and others have found that the psychiatric problems in carriers start much earlier than the neurological problems associated with FXTAS. ${ }^{14}$ Cordeiro et al have found that $70.6 \%$ of children, adolescents, and young adults with the premutation demonstrated at least one anxiety disorder compared to $22.6 \%$ of controls and $8 \%$ in the general population. ${ }^{15}$ Both depression and anxiety can increase with age in women with the premutation and there is a curvilinear association with the CGG repeat number and those with 70 to 100 repeats are at greatest risk for these psychiatric problems. ${ }^{16,17}$ Once an individual develops FXTAS, psychiatric problems progress faster in women compared to men although the motor problems progress faster in men compared to women. ${ }^{18}$

FXAND also includes ADHD which is common in premutation males in childhood and the attention problems can persist into adulthood and become worse when executive function problems develop with aging. ${ }^{19-21}$ Even autism spectrum disorder (ASD) can be seen in about $15 \%$ of premutation boys. ${ }^{19}$ Recent studies have documented the broad autism phenotype (BAP) in approximately 50\% of women with the premutation. ${ }^{22}$ Some of the BAP features include pragmatic language deficits, obsessive compulsive features and dysregulation in coordinating language fluency and eye movement patterns during rapid naming tasks demonstrating deficits in executive function that are subclinical. $^{23-25}$

FXPOI first discovered in 1991, is the most common genetic causes of ovarian dysfunction in women and develops in approximately $20 \%$ of the premutation carriers. $^{26-28}$ The two main criteria taken into consideration when making diagnosis of FXPOI are irregular or absent menstruation before age 40 and menopausal levels of Follicular Stimulating Hormone (FSH). The clinical onset of FXPOI depends on the number of CGG repeats and is maximum when the CGG repeats are in the midrange (80-100 repeats). The important point to note here is that on occasion women with FXPOI are sometimes able to conceive. ${ }^{27,29,30}$ Before the onset of FXPOI, eggs can be retrieved and In vitro fertilization (IVF) can be utilized to identify normal embryos that can then be implanted, thereby avoiding a fetus with FXS.

Fragile X-associated tremor/ataxia syndrome (FXTAS) is one of the premutation disorders with a wide spectrum of clinical features grouped into major and minor criteria for making the diagnosis. The four major diagnostic criteria include intention tremor, cerebellar ataxia, white matter hyperintensities seen on MRI in the middle cerebellar peduncles (MCP), and intranuclear inclusions in central nervous system (CNS) seen in postmortem studies. $^{31,32}$ The minor diagnostic criteria include Parkinsonism, peripheral neuropathy, executive function and memory deficits in addition to white matter 
hyperintensities in the splenium of the corpus callosum and brain atrophy. $5,31,33$

\section{Interventions}

The treatment of premutation conditions is challenging not only because of the multiple coexisting problems within the same individual but also because of its hereditary nature and the lack of a cure for many of these premutation problems. Therefore, a holistic approach is required when formulating a management plan for the carriers and the goal should be to identify and treat all the psychological, medical and behavioral issues faced by the carriers. In this section, we will enumerate the existing effective treatment options under three categories namely psychopharmacological, medical and behavioral interventions.

\section{Psychopharmacological and Medical Interventions}

The combination of pharmacotherapy and psychotherapy is an effective approach to manage depression and anxiety problems seen in patients with FXAND and selective serotonin reuptake inhibitors (SSRIs) and serotonin and norepinephrine reuptake inhibitors (SNRIs) are the first line treatment options in pharmacotherapy. ${ }^{11,34}$ Some of the SSRIs routinely used are sertraline, fluvoxamine, paroxetine, escitalopram and fluoxetine. Escitalopram and sertraline have a better side effect profile and fewer drug interactions due to minimal inhibitory action on cytochrome P450 (CYP450) enzyme system and hence often become drugs of choice in patients using multiple medications. ${ }^{35}$ However, if pain symptoms are a component of FXAND then use of an SNRI initially, such as duloxetine or venlafaxine is recommended to treat both the pain and the depression/anxiety. ${ }^{36}$ The SNRIs may also be more helpful when ADHD is a component of FXAND in adulthood. The treatment of psychiatric problems should also include psychotherapy. ${ }^{37}$

In childhood the combination of counseling and medication to treat ADHD is essential. In childhood the drugs of choice for ADHD are stimulants, specifically methylphenidate or dexamphetamine, although typically they are not used until 5 yo or older since irritability may occur at younger ages. If stimulants are not tolerated, nonstimulants such as atomoxetine or alpha 2 adrenergic agonists (clonidine, guanfacine) or even modafinil can be helpful. ${ }^{38}$ Guanfacine has a calming effect which can be particularly helpful for those children who are overstimulated by environmental stimuli especially in childhood. It can also be used in children who are younger than 5yo for their hyperactivity or hyperarousal since stimulants are typically not used under 5 years old. ${ }^{39}$

Women who are identified as carriers should be screened early for FXPOI and should be treated appropriately once diagnosed. Hormone replacement therapy particularly estrogen replacement treatments have shown beneficial effects in regards to menopausal symptoms. ${ }^{27,29}$ Additionally, estrogen helps in attenuating symptoms of osteoporosis in women with FXPOI. ${ }^{40}$ The ideal route of administration of estrogen is transdermal or transvaginal as the risk of thromboembolism and cardiovascular problems is less when estrogen is given via these routes as compared to when estrogen is given by the oral route. ${ }^{41}$ After a diagnosis of FXPOI sometimes pregnancy can occur and this is why the disorder originally named Fragile $\mathrm{X}$-associated ovarian failure was renamed FXPOI. ${ }^{29}$ Moreover, women carriers often have cooccurring problems such as anxiety, hypothyroidism, migraine among others that also need proper evaluation and treatment. ${ }^{42}$

For FXTAS, we can categorize the drugs used in its treatment into four broad groups: drugs for movement disorders (tremor and ataxia), drugs for cognitive dysfunction, drugs for psychiatric issues and drugs for neuropathic pain. Medications used for tremor are propranolol or other beta blockers, primidone, topiramate, gabapentin and medications used for ataxia are riluzole, amantadine, buspirone, varenicline, Sinemet. ${ }^{33,43}$ If parkinsonian symptoms such as resting tremor, masked facies or shuffling gait are seen in patients in FXTAS then medication used for Parkinson's disease, such as Sinemet, are often helpful. For cognitive dysfunction or memory problems medications used for mild cognitive impairment (MCI) or dementia include donepezil, rivastigmine, galantamine, and memantine. The only medication that has been studied in a controlled trial in FXTAS for cognitive changes is memantine, an N-methyl-d-aspartate (NMDA) receptor antagonist, and the trial lasted for a year. ${ }^{44}$ Although memantine was not helpful for tremor or ataxia, it was helpful for auditory processing, attention and memory as assessed by event related potential (ERP) studies in this controlled trial. ${ }^{45,46}$ Therefore, memantine is often used in individuals with the premutation and FXTAS who are experiencing cognitive problems.

For neuropathic pain we can use gabapentin, pregabalin, topical cannabidiol (CBD) or Lidocaine patches., ${ }^{3,47,48}$ Allopregnanolone, a neurosteroid that is a byproduct of 
progesterone, and a potent $\mathrm{GABA}_{\mathrm{A}}$ receptor allosteric modulator, has possible neurogenesis potential and neuroprotective effects in premutation carriers. ${ }^{47}$ Allopregnanolone has been studied in an open label study in 6 patients with FXTAS who received this medication IV once a week for 3 months. ${ }^{49}$ In one patient the neuropathy symptoms disappeared and in the group there were significant improvements in ERP studies, executive function deficits and episodic memory, however the tremor and ataxia did not significantly improve. ${ }^{49}$ The development of an oral allopregnanolone preparation will allow further treatment studies in those with FXTAS.

For the psychiatric problems in FXTAS the use of SSRIs are recommended as noted above. ${ }^{3}$ According to one open labeled clinical trial, citicoline is a fairly new drug that has shown promising effects in patients with FXTAS and is relatively safe and is well tolerated. In this trial $1000 \mathrm{mg}$ of citicoline was administered as an open label study to ten patients for a year and various parameters were measured at 3,6 and 12 month intervals. Patients either showed no deterioration or showed significant improvement on various motor as well as cognitive scales. $^{50}$

\section{Behavioral Interventions}

Behavioral interventions are used as adjunctive therapies that are tailored to meet the needs of the affected premutation carrier. Cognitive behavioral therapy (CBT) is one of the most effective behavioral therapies used for depression and anxiety disorders. The different components of CBT are cognitive therapy, behavioral therapy and third wave of CBT which covers mindfulness, acceptance and dialectical behavioral therapy. ${ }^{51}$ According to one meta-analysis, CBT is effective when given in one on one sessions by a non-physician to the patients with depression and anxiety issues, although not studied in FXTAS. ${ }^{52}$ Additionally, CBT helps in improving the core symptoms of ADHD in adults and is also used for substance abuse, chronic pain and insomnia. ${ }^{51,53}$ However, this therapy has not been studied in a controlled trial in those with FXTAS.

Biofeedback and neurofeedback techniques are operant conditioning treatments having various applications including treatment of anxiety, depression, ADHD, and substance abuse among others. ${ }^{3,54}$ The difference between the two is that biofeedback does not involve the training of the brain whereas neurofeedback does. ${ }^{54,55}$ Biofeedback and neurofeedback measure brain activity, heart rate, respiratory rate and skin temperature with the help of sensors through human-computer interaction. ${ }^{3,56,57}$ These techniques aim at increasing the consciousness of an individual for various physiological parameters and result in improved health outcomes by allowing the individual to reinforce the positive experiences. According to one pilot study, Respiratory Sinus Arrhythmia (RSA) biofeedback portable device was helpful in curbing the symptoms related to anxiety disorders, but it has not been studied in those with FXTAS nor in any premutation carriers. ${ }^{58}$

\section{RNA Toxicity}

Studies have shown that premutation neurons demonstrate oxidative stress and they die more easily in culture presumably because of the RNA toxicity that binds proteins important for neuronal function, and there is calcium dysregulation and mitochondrial dysfunction with the production of reactive oxygen species (ROS). ${ }^{59-61}$ Cao et al demonstrated that the abnormal spikes in premutation neurons in culture improved with allopregnanolone treatment used in the culture which stimulated the allopregnanolone study in those with FXTAS mentioned above. ${ }^{62,63}$

Causes of premutation toxicity include repeat associated non AUG (RAN) translation that occurs in some premutation carriers leading to the production of FMRpolyG, a protein that is toxic to cells. ${ }^{64}$ Other problems associated with the premutation include altered zinc and iron homeostasis and enhanced iron deposition in the brain of carriers. ${ }^{65-68}$ The addition of the iron chelator deferoxamine mesylate to fibroblasts from older FXTAS carriers showed a significant improvement of complex IV activity in the mitochondria. ${ }^{66}$ Many papers have documented mitochondrial abnormalities and oxidative stress in the fibroblasts or blood of premutation carriers even before the onset of FXTAS. ${ }^{65,66,69}$ Song et al have studied the use of a variety of antioxidants such as trolox (vitamin E analogue), quercetin, epigallocatechin gallate (EGCG), dimethyl sulfoxide, a superoxide or hydroxyl radical scavenger, a glutathione peroxidase analog (acetyl-L-cysteine (NAC)), L ascorbic acid, and found a variable benefit in 31 premutation fibroblast lines, 8 of which came from patients with FXTAS. Song et al also found a significant negative effect of ethanol on mitochondrial function in these fibroblast lines. ${ }^{60}$ There are also several reports of environmental toxins that accelerate FXTAS symptoms or clinical deterioration and these include the isofloranes in general anesthesia, illicit drugs such as cocaine, methamphetamines, methadone, or opioids, chemotherapy and environmental toxins. ${ }^{70-74}$ Smoking can also worsen 
oxidative stress and has been shown to lower the age of onset of FXPOI in women. ${ }^{75}$ Whenever possible general anesthesia must be avoided and if needed in emergencies, the safest option, such as propofol, should be used, as general anesthetic agents can cause decline in cognitive function in FXTAS. ${ }^{76}$

Opioids are a particular problem in those with FXTAS because pain symptoms are common, and if opioids are used for pain, patients often become addicted and subsequently white matter microstructure can become disrupted in opiate addiction. ${ }^{77}$ One case report of opioid overdose has been reported in a woman with FXTAS who almost died. ${ }^{78}$ Kogan et al and Dorn et al found increased rates of excessive alcohol use in premutation males, perhaps as a treatment for the depression/ anxiety that is increased in carriers. ${ }^{79,80}$ However, excessive alcohol can exacerbate white matter disease and escalate FXTAS progression both at a cellular level ${ }^{60}$ and in patients with FXTAS. $^{72}$ Alcoholism likely contributed to the development of FXTAS in a 65 year old man with an unmethylated full mutation. ${ }^{81}$ In addition, a 36 year old male with the premutation and both alcohol and methamphetamine addiction developed FXTAS in his early 30s and his autopsy after death demonstrated the inclusions of FXTAS so this is the youngest patient known with FXTAS. ${ }^{43}$

\section{Lifestyle Modifications}

Because of the case studies that have shown early onset or deterioration in neurological symptoms with exposure to excessive alcohol or general anesthesia or environmental toxins mentioned above we recommend that carriers avoid environmental toxins and avoid excessive alcohol intake. ${ }^{82,83}$ For many patients this means a significant change in their lifestyle particularly in those who have had daily drinking. Lifestyle modifications in premutation carriers involve alteration of long-term habits. For instance, increasing exercise is difficult for many but it is helpful for mitochondrial function, it reduces inflammation, it stimulates neurogenesis and it strengthens muscles and all of these effects are important for those with FXTAS. ${ }^{84}$ Patients should also be advised to avoid specific toxins and increase consumption of antioxidants that have the potential for improving oxidative stress and ROS, which will hopefully slow the progression of FXTAS. ${ }^{3}$

Other toxins that can accelerate neurodegenerative process in premutation carriers and hence should be avoided are smoking, alcohol and marijuana. ${ }^{3,44}$ Smoking also decreases the reproductive lifespan in both female carriers as well as female non-carriers. ${ }^{75}$

\section{Physical Activity and Mindfulness Meditation}

Exercise is one of the most effective non-pharmacological methods that promote neurogenesis and is beneficial in premutation individuals. ${ }^{3}$ Exercise programs can be developed according to the needs and capacities of an individual. There are many studies that confirm the benefits of the exercise in older adults. Exercise uplifts mood and improves cognitive functioning in individuals with mild cognitive impairment or dementia. ${ }^{76,85}$ Exercise also enhances neuroplasticity and improves spatial learning and memory by altering excitatory synaptic connections. ${ }^{86}$ Exercise also lowers inflammation and this also may be helpful for patients with FXTAS.

Mindfulness based stress reduction (MSBR) is a unique eight-week program that integrates various methods such as mindfulness meditation, yoga and several other techniques for relaxation. It helps people to cope with depression, anxiety, stress and chronic pain. ${ }^{87}$ It could also be used for substance abuse and is basically a non-judgmental approach to accept one's psyche to regulate emotions, thoughts and behavior. ${ }^{88}$

MSBR is as effective as CBT in the treatment of chronic low back pain and also a cost effective option for the treatment of chronic low back pain. ${ }^{89,90}$ In addition, MSBR with or without app based technology has shown to alleviate stress that is common in the mothers of children with FXS. ${ }^{91}$

\section{Oxidative Stress and Antioxidants}

Premutation carriers may be more vulnerable to oxidative stress due to abnormal mitochondrial function. Dysfunctional mitochondria particularly in FXTAS in both the central nervous system (CNS) and non-CNS tissues could lead to decreased adenosine 5-triphosphate (ATP) production and ultimately affects oxidative phosphorylation (OXPHOS) capacity of the cells. The brain is the most affected organ as the brain cells are highly dependent on OXPHOS for energy production. ${ }^{69}$

Antioxidants are the substances that reduce oxidative stress by inhibiting production of free radicals. Polussa et al have briefly described some of the antioxidants such as vitamin $\mathrm{E}$, vitamin $\mathrm{B} 9$, melatonin, coenzyme Q10, ginseng, omega 3s, epigallocatechin-3-gallate (EGCG), anthocyanins, 
$\mathrm{N}$-acetyl-L cysteine (NAC) and their role in reversing oxidative stress in premutation carriers. ${ }^{3}$ Furthermore, curcumin and sulforaphane are also useful antioxidant supplements that could be used in neurodegenerative diseases. ${ }^{92-94}$ Recently, Napoli et al have studied sulforaphane in fibroblast cultures from those with FXTAS and documented that sulforaphane improved oxidative stress and mitochondrial dysfunction by turning on the $N r f 2$ cellular antioxidant system. ${ }^{94}$ Currently an open labeled study of sulforaphane's effect on molecular biomarkers is being carried out in 15 individuals with FXTAS.

Farnesol has been shown to ameliorate oxidative stress in animal models with Parkinson's disease (PD). ${ }^{95}$ Farnesol, usually used to flavor food and make perfume, has recently been shown to reverse symptoms of Parkinson's disease which is a promising discovery. ${ }^{95}$ It prevents the death of dopaminergic neurons in the brain by deactivating parkin-interacting substrate (PARIS) which is implicated as one of the factors in causing the disease. ${ }^{95}$ Additionally, alteration of gut microbiota has proven to alleviate oxidative damage in the brain signifying the importance of consumption of probiotics. ${ }^{96,97}$

Alpha-tocopherol, vitamin E, possesses antioxidant as well as anti-inflammatory properties. ${ }^{98}$ Grundman et al have found that it prevents beta amyloid induced damage of neurons in Alzheimer's disease and improves dementia in animal models. ${ }^{99}$ Crouzin et al have found that alpha tocopherol treated cultured hippocampus neurons have exhibited more resistance to oxidative damage. ${ }^{100}$ Thus, vitamin $E$ could be used in premutation carriers due to the above-mentioned benefits.

Folic acid, vitamin B9, given in a dose of $10 \mathrm{mg}$ per day was shown to improve behaviors in males with FXS. $^{101}$ Folic acid has a key role in prevention of Alzheimer disease and it also reduces brain atrophy in elderly. ${ }^{3,102}$ Hence, folic acid is often prescribed along with vitamin B12 to older premutation individuals, because of their neuroprotective benefits. ${ }^{56}$

Melatonin combats oxidative stress by selectively attaining its highest concentration in mitochondria (Mitochondria targeted antioxidants) and this property gives melatonin an upper hand in scavenging reactive oxygen species (ROS) effectively as compared to the conventional antioxidants. ${ }^{103}$ Melatonin has many applications including its use for sleep disorders, nocturnal hypertension, Parkinson's disease and Alzheimer disease, although controlled trials are needed to document benefits in carriers. ${ }^{104}$ During ovulation there is a surge in ROS which is required for oocyte maturation and rupture of the follicle but excessive ROS can lead to ovarian dysfunction and infertility problems hence a good antioxidant is important to keep this oxidative stress under check. Melatonin is one such antioxidant that effectively works on ROS in the ovaries through unknown mechanisms and hence reduces ovarian aging. Melatonin also improves outcomes of in-vitro fertilization in women with infertility problems probably by improving the quality of oocytes. ${ }^{105}$

Coenzyme Q 10 (CoQ10), a part of the mitochondrial transport chain, is another antioxidant that is consumed widely as a dietary supplement. ${ }^{106,107}$ The cellular level defects seen in Alzheimer and Parkinson's disease have been attributed to the deficiency of this enzyme. ${ }^{108}$ Mitoquinone (Mito Q) another powerful antioxidant made my combining endogenous CoQ10 and lipophilic triphenyl phosphonium cation (TPP) also attains a high concentration in mitochondria like melatonin and thereby prevents local oxidative damage. ${ }^{103,109}$

Curcumin found in turmeric has antioxidant, antiinflammatory and neuroprotective benefits. According to one clinical trial, it has been shown to reduce amyloid and tau deposition in brain, signifying its positive impact on mood and memory. ${ }^{110}$ Curcumin's interaction with the gut microbiota increases good bacteria and reduces pathologic bacteria. ${ }^{111}$

Asian or Korean ginseng is famous by the name panax ginseng and is an effective antioxidant. Other than antioxidant properties it also demonstrates anti-inflammatory properties and can benefit brain function. ${ }^{112}$ Omega 3 s especially marine omega 3 has shown promising results in improving psychiatric health and its deficiency has been reported in various disorders such as ADHD, depression and autism. ${ }^{113}$

EGCG, a major component of green tea, has antioxidant, anti-inflammatory, anti-cancer and anti-fibrosis effects. ${ }^{114,115}$ EGCG also has neuroprotective properties and can be beneficial in Alzheimer's disease and other neurodegenerative diseases. ${ }^{116}$ Anthocyanins are a group of antioxidants that are commonly obtained from plant sources such as grapes, blueberries and cabbage. ${ }^{117}$ Anthocyanins might also help in reducing weight and tackling obesity issues. ${ }^{118}$

$\mathrm{N}$-acetyl-1-cysteine, an antioxidant with neuroprotective and anti-inflammatory properties, has shown promising results in older rats and could have potential implications in preventing neurological problems in the geriatric population. ${ }^{119}$ It also increases the levels of glutathione (GSH) in brain cells, which is a part of an endogenous antioxidant enzyme system. ${ }^{3,119}$ 
To date no consolidated data about the beneficial effects of these antioxidants in premutation carriers has been elicited. The only antioxidant that has been studied in premutation tissues is sulforaphane as noted above. ${ }^{94}$ Metformin is an antioxidant that is also used as a targeted treatment in those with FXS because it lowers the mTOR pathway that is upregulated when FMRP is lowered. ${ }^{120,121}$ It is primarily used as a treatment for type 2 diabetes and it can also help to decrease the appetite and treat obesity which is beneficial for many patients with FXS and obesity. ${ }^{122}$ Some premutation carriers with obesity or type 2 diabetes have found this medication helpful but the antioxidant effects and the protection against cancer may also be helpful for premutation carriers particularly those with lowered levels of FMRP. ${ }^{121}$ Controlled trials are needed in selected premutation carriers who may benefit from metformin.

\section{Future Studies}

Currently CBD is used at times to treat pain symptoms in those with the premutation but it is also an antioxidant and it is known to reduce inflammation and also have neuroprotective properties. ${ }^{123,124} \mathrm{CBD}$ has been helpful in treatment of patients with FXS in an open label study and most recently in a controlled trial for those that are fully methylated with a full mutation ${ }^{125}$ (Berry-Kravis et al under review). It is known to improve anxiety and other types of psychopathology in the general population but it needs to be studied in premutation carriers with FXAND and perhaps for pain in those with FXTAS. ${ }^{126}$ A recently developed oral allopregnanolone preparation is likely to be helpful in those with FXTAS because of the benefits seen in the IV allopregnanolone study of patients with FXTAS. ${ }^{49}$ Therefore, a controlled trial of this newly developed treatment which improves mitochondrial function in FXTAS is warranted.

Another new treatment which is pending FDA approval for research in FXTAS is Anavex 2-73, a sigma 1 agonist that works in the endoplasmic reticulum and mitochondrial interface. It can reduce oxidative stress, alleviate calcium dysregulation in neurons and improve mitochondrial function which is greatly needed in FXTAS and in other disorders. ${ }^{127,128}$ Anavex 2-73 also helps other cellular dysfunctions including proteostasis, autophagy and neuroinflammation that are present in neurodegenerative and neurodevelopmental disorders. ${ }^{129,130}$ It has been efficacious in animal models and human studies in Rett syndrome (unpublished), studies in Alzheimer Disease, in Parkinson's Disease Dementia (unpublished) and most recently in rescuing hyperactivity and other behaviors in the KO FXS mouse. ${ }^{127,131,132}$ Soon controlled trials of Anavex 2-73 will be studied in those with FXTAS. In the future gene therapy will deliver treatments using CRISPR/ Cas 9 modified genes or perhaps a silencing mechanism to turn off the excessive mRNA leading to toxicity, but animal studies must be carried out before human trials.

\section{Summary}

An effective management plan required for improving the health of the premutation patients must follow a holistic approach including a thorough screening of psychiatric problems as documented in FXAND. Patients should be educated about various existing medical treatment options in addition to various behavioral interventions such as CBT and numerous biofeedback techniques. Moreover, patients should also be made aware of the importance of physical activity, meditation techniques and the beneficial effects of various antioxidants in slowing the progression of premutation disorders. Careful family history may help carriers understand the diseases that run in the family. When there is a strong family history of FXTAS or FXPOI then the chances that these problems will eventually occur in other carriers in the family are high. The education of all family members regarding the molecular effects of the premutation, the importance of the $\mathrm{CGG}$ repeat number and the influence of AGG interruptions and background genetic effects should be carried out so that lifestyle decisions can be made early in adult life.

\section{Acknowledgments}

We thank Abijeet Singh Mehta for helping with endnote and proof reading. This study was funded by NICHD HD036071, the Tides Foundation, the MIND Institute IDDRC (grant U54 HD079125), and the National Center for Advancing Translational Sciences and National Institutes of Health (grant UL1 TR001860).

\section{Disclosure}

Dr Randi Hagerman reports grants from NICHD, during the conduct of the study; has received funding from Zynerba and the Azrieli Foundation for treatment studies in FXS. The authors report no other conflicts of interest in this work.

\section{References}

1. Tassone F, Iong K, Tong T-H, et al. FMR1 CGG allele size and prevalence ascertained through newborn screening in the United States. Genome Med. 2012;4(12):100. doi:10.1186/gm401 
2. Seltzer MM, Baker MW, Hong J, et al. Prevalence of CGG expansions of the FMR1 gene in a US population-based sample. Am J Med Genet Part B. 2012;159B(5):589-597. doi:10.1002/ajmg.b.32065

3. Polussa J, Schneider A, Hagerman R. Molecular advances leading to treatment implications for fragile $\mathrm{X}$ premutation carriers. Brain Disord Ther. 2014;3:100011.

4. Tassone F, Hagerman RJ, Taylor AK, et al. Elevated levels of FMR1 mRNA in carrier males: a new mechanism of involvement in the fragile-X syndrome. Am J Hum Genet. 2000;66(1):6-15. doi: $10.1086 / 302720$

5. Hagerman RJ, Hagerman P. Fragile X-associated tremor/ataxia syndrome - features, mechanisms and management. Nat Rev Neurol. 2016;12(7):403-412. doi:10.1038/nrneurol.2016.82

6. Johnson K, Herring J, Richstein J. Fragile X premutation associated conditions (FXPAC). Front Pediatr. 2020;8:266. doi:10.3389/fped.2020.00266

7. Tassanakijpanich N, Cohen J, Cohen R, et al. Cardiovascular problems in the fragile $\mathrm{X}$ premutation. Front Genet. 2020;11:586910. doi:10.3389/fgene.2020.586910

8. Tassanakijpanich N, McKenzie FJ, McLennan YA, et al. Hypermobile Ehlers-Danlos syndrome (hEDS) phenotype in fragile X premutation carriers: case series. J Med Genet. 2021; jmedgenet-2020-107609. doi:10.1136/jmedgenet-2020-107609

9. Richter JD, Zhao X. The molecular biology of FMRP: new insights into fragile X syndrome. Nat Rev Neurosci. 2021;22 (4):209-222. doi:10.1038/s41583-021-00432-0

10. Cabal-Herrera AM, Saldarriaga-Gil W, Salcedo-Arellano MJ, et al. Fragile $X$ associated neuropsychiatric disorders in a male without FXTAS. Intractable Rare Dis Res. 2020;9(2):113-118. doi:10.5582/irdr.2020.01028

11. Hagerman RJ, Protic D, Rajaratnam A, et al. Fragile X-associated neuropsychiatric disorders (FXAND). Front Psychiatry. 2018;9:564. doi:10.3389/fpsyt.2018.00564

12. Tan MM, Dy JB, Salcedo-Arellano MJ, Tassone F, Hagerman RJ. Fragile X- associated neuropsychiatric disorders: a case report. Future Neurol. 2019;14(2):FNL14.

13. Bourgeois JA, Seritan AL, Casillas EM, et al. Lifetime prevalence of mood and anxiety disorders in fragile $\mathrm{X}$ premutation carriers. J Clin Psychiatry. 2011;72(2):175-182. doi:10.4088/JCP.09m05407blu

14. Seritan AL, Ortigas M, Seritan S, Bourgeois JJ, Hagerman R. Psychiatric disorders associated with FXTAS. Curr Psychiatry Rev. 2013;9(1):59-64.

15. Cordeiro L, Abucayan F, Hagerman R, et al. Anxiety disorders in fragile $\mathrm{X}$ premutation carriers: preliminary characterization of probands and non-probands. Intract Rare Dis Res. 2015;4:123-130. doi:10.5582/irdr.2015.01029

16. Roberts JE, Tonnsen BL, McCary LM, et al. Trajectory and predictors of depression and anxiety disorders in mothers with the FMR1 premutation. Biol Psychiatry. 2016;79(10):850-857. doi:10.1016/j.biopsych.2015.07.015

17. Roberts JE, Mankowski JB, Sideris J, et al. Trajectories and predictors of the development of very young boys with fragile $\mathrm{X}$ syndrome. J Pediatr Psychol. 2009;34(8):827-836. doi:10.1093/jpepsy/jsn129

18. Loesch DZ, Tassone F, Atkinson A, et al. Differential progression of motor dysfunction between male and female fragile $\mathrm{X}$ premutation carriers reveals novel aspects of sex-specific neural involvement. Front Mol Biosci. 2020;7:577246. doi:10.3389/ fmolb.2020.577246

19. Farzin F, Perry H, Hessl D, et al. Autism spectrum disorders and attention-deficit/hyperactivity disorder in boys with the fragile $\mathrm{X}$ premutation. J Dev Behav Pediatr. 2006;27(2 Suppl):S137-S144. doi:10.1097/00004703-200604002-00012

20. Hunter JE, Epstein MP, Tinker SW, et al. The FMR1 premutation and attention-deficit hyperactivity disorder (ADHD): evidence for a complex inheritance. Behav Genet. 2012;42(3):415-422. doi:10.1007/s10519-011-9520-z
21. Grigsby J, Brega AG, Bennett RE, et al. Clinically significant psychiatric symptoms among male carriers of the fragile $\mathrm{X}$ premutation, with and without FXTAS, and the mediating influence of executive functioning. Clin Neuropsychol. 2016;30 (6):944-959. doi:10.1080/13854046.2016.1185100

22. Nayar K, Sealock JM, Maltman N, et al. Elevated polygenic burden for autism spectrum disorder is associated with the broad autism phenotype in mothers of individuals with autism spectrum disorder. Biol Psychiatry. 2021;89(5):476-485. doi:10.1016/j.biopsych.2020.08.029

23. Klusek J, Schmidt J, Fairchild AJ, et al. Altered sensitivity to social gaze in the FMR1 premutation and pragmatic language competence. J Neurodev Disord. 2017;9(1):31. doi:10.1186/s11689-017-9211-z

24. Losh M, Martin GE, Klusek J, et al. Pragmatic Language in autism and fragile $\mathrm{X}$ syndrome: genetic and clinical applications. Perspect Lang Learn Educ. 2012;19:48-55. doi:10.1044/1le19.2.48

25. Schneider A, Johnston C, Tassone F, et al. Broad autism spectrum and obsessive-compulsive symptoms in adults with the fragile $\mathrm{X}$ premutation. Clin Neuropsychol. 2016;30(6):929-943. doi:10.1080/13854046.2016.1189536

26. Cronister A, Schreiner R, Wittenberger M, et al. Heterozygous fragile $\mathrm{X}$ female: historical, physical, cognitive, and cytogenetic features. Am J Med Genet. 1991;38(2-3):269-274. doi:10.1002/ ajmg.1320380221

27. Hipp HS, Charen KH, Spencer JB, et al. Reproductive and gynecologic care of women with fragile X primary ovarian insufficiency (FXPOI). Menopause. 2016;23(9):993-999. doi:10.1097/ GME.0000000000000658

28. Fink DA, Nelson LM, Pyeritz R, et al. Fragile X associated primary ovarian insufficiency (FXPOI): case report and literature review. Front Genet. 2018;9:529. doi:10.3389/fgene.2018.00529

29. Hunter JE, Berry-Kravis E, Hipp H, Todd PK, et al. Women's issues in Fragile $\mathrm{X}$ spectrum disorders. Fragile $X$ syndrome and premutation disorders. Clin Dev Med. 2020:75-82.

30. Sullivan SD, Welt C, Sherman S. FMR1 and the continuum of primary ovarian insufficiency. Semin Reprod Med. 2011;29 (4):299-307. doi:10.1055/s-0031-1280915

31. Hall DA, Birch RC, Anheim M, et al. Emerging topics in FXTAS. J Neurodev Disord. 2014;6(1):31. doi:10.1186/1866-1955-6-31

32. Tassone F, Greco CM, Hunsaker MR, et al. Neuropathological, clinical and molecular pathology in female fragile X premutation carriers with and without FXTAS. Genes Brain Behav. 2012;11 (5):577-585. doi:10.1111/j.1601-183X.2012.00779.x

33. Martinez-Cerdeno V. FXTAS new advances and treatments, in Fragile X syndrome and premutation disorders. In: Clinics in Developmental Medicinez. Mac Keith Press; 2020:83-96.

34. DeMartini J, Patel G, Fancher TL. Generalized anxiety disorder. Ann Intern Med. 2019;170(7):Itc49-itc64. doi:10.7326/ AITC201904020

35. $\mathrm{Ng} \mathrm{CW}$, How $\mathrm{CH}, \mathrm{Ng}$ YP. Managing depression in primary care. Singapore Med J. 2017;58(8):459-466. doi:10.11622/ smedj.2017080

36. Kirwin JL, Gören JL. Duloxetine: a dual serotonin-norepinephrine reuptake inhibitor for treatment of major depressive disorder. Pharmacotherapy. 2005;25(3):396-410. doi:10.1592/ phco.25.3.396.61600

37. Buoli M, Serati M, Cahn W. Alternative pharmacological strategies for adult ADHD treatment: a systematic review. Expert Rev Neurother. 2016;16(2):131-144. doi:10.1586/14737175.2016.1135735

38. Geffen J, Forster K. Treatment of adult ADHD: a clinical perspective. Ther Adv Psychopharmacol. 2018;8(1):25-32. doi: $10.1177 / 2045125317734977$

39. Hagerman RJ, Protic D, Berry-Kravis EM. Medical, psychopharmacological, and targeted treatment for FXS. Fragile X syndrome and premutation disorders. Clin Dev Med. 2020:41-57. 
40. Li L, Wang Z. Ovarian aging and osteoporosis. Adv Exp Med Biol. 2018;1086:199-215.

41. Sullivan SD, Sarrel PM, Nelson LM. Hormone replacement therapy in young women with primary ovarian insufficiency and early menopause. Fertil Steril. 2016;106(7):1588-1599.

42. Allen EG, Charen K, Hipp HS, et al. Clustering of comorbid conditions among women who carry an FMR1 premutation. Genet Med. 2020;22(4):758-766. doi:10.1038/s41436-019-0733-5

43. Martínez-Cerdeño V, Lechpammer M, Lott A, et al. Fragile $\mathrm{X}$-associated tremor/ataxia syndrome in a man in his $30 \mathrm{~s}$. JAMA Neurol. 2015;72(9):1070-1073. doi:10.1001/jamaneurol.2015.1138

44. Seritan AL, Kim K, Benjamin I, et al. Risk factors for cognitive impairment in fragile $\mathrm{X}$-associated tremor/ataxia syndrome. J Geriatr Psychiatry Neurol. 2016;29(6):328-337. doi:10.1177/ 0891988716666379

45. Yang JC, Rodriguez A, Royston A, et al. Memantine improves attentional processes in fragile $\mathrm{X}$-associated tremor/ataxia syndrome: electrophysiological evidence from a randomized controlled trial. Sci Rep. 2016;6:21719. doi:10.1038/srep21719

46. Yang JC, Niu Y-Q, Simon C, et al. Memantine effects on verbal memory in fragile X-associated tremor/ataxia syndrome (FXTAS): a double-blind brain potential study. Neuropsychopharmacology. 2014;39(12):2760-2768. doi:10.1038/npp.2014.122

47. Cabal-Herrera AM, Tassanakijpanich N, Salcedo-Arellano MJ, et al. Fragile X-associated tremor/ataxia syndrome (FXTAS): pathophysiology and clinical implications. Int $J$ Mol Sci. 2020;21(12):4391. doi:10.3390/ijms21124391

48. Salcedo-Arellano MJ, Hagerman RJ, Martinez-Cerdeno V. [Fragile $\mathrm{X}$ associated tremor/ataxia syndrome: its clinical presentation, pathology, and treatment]. Rev Neurol. 2019;68 (5):199-206. Spanish.

49. Wang JY, Trivedi AM, Carrillo NR, et al. Open-label allopregnanolone treatment of men with fragile X-associated tremor/ataxia syndrome. Neurotherapeutics. 2017;14(4):1073-1083. doi:10.100 7/s13311-017-0555-6

50. Hall DA, Robertson EE, Leehey M, et al. Open-label pilot clinical trial of citicoline for fragile $\mathrm{X}$-associated tremor/ataxia syndrome (FXTAS). PLoS One. 2020;15(2):e0225191. doi:10.1371/journal. pone. 0225191

51. Thoma N, Pilecki B, McKay D. Contemporary cognitive behavior therapy: a review of theory, history, and evidence. Psychodyn Psychiatry. 2015;43(3):423-461. doi:10.1521/ pdps.2015.43.3.423

52. Zhang A, Borhneimer LA, Weaver A, et al. Cognitive behavioral therapy for primary care depression and anxiety: a secondary meta-analytic review using robust variance estimation in meta-regression. $J$ Behav Med. 2019;42(6):1117-1141. doi:10.1007/s10865-019-00046-z

53. Pan MR, Huang F, Zhao M-J, et al. A comparison of efficacy between cognitive behavioral therapy (CBT) and CBT combined with medication in adults with attention-deficit/hyperactivity disorder (ADHD). Psychiatry Res. 2019;279:23-33. doi:10.1016/j. psychres.2019.06.040

54. Markiewcz R. The use of EEG biofeedback/neurofeedback in psychiatric rehabilitation. Psychiatr Pol. 2017;51(6):1095-1106. doi:10.12740/PP/68919

55. Giggins OM, Persson UM, Caulfield B. Biofeedback in rehabilitation. J Neuroeng Rehabil. 2013;10:60. doi:10.1186/ 1743-0003-10-60

56. Batail JM, Bioulac S, Cabestaing F, et al. EEG neurofeedback research: a fertile ground for psychiatry? Encephale. 2019;45 (3):245-255. doi:10.1016/j.encep.2019.02.001

57. Malik K, Dua A. Biofeedback. In: StatPearls. Treasure Island (FL): StatPearls Publishing Copyright (C) 2021, StatPearls Publishing LLC.; 2021.
58. Reiner R. Integrating a portable biofeedback device into clinical practice for patients with anxiety disorders: results of a pilot study. Appl Psychophysiol Biofeedback. 2008;33(1):55-61. doi:10.1007/s10484-007-9046-6

59. Chen Y, Tassone F, Berman RF, et al. Murine hippocampal neurons expressing Fmr1 gene premutations show early developmental deficits and late degeneration. Hum Mol Genet. 2010;19 (1):196-208. doi:10.1093/hmg/ddp479

60. Song G, Napoli E, Wong S, et al. Altered redox mitochondrial biology in the neurodegenerative disorder fragile X-tremor/ataxia syndrome: use of antioxidants in precision medicine. Mol Med. 2016;22:548-559. doi:10.2119/molmed.2016.00122

61. Randol JL, Bzymek M, Hagerman PJ. Molecular advances in fragile $\mathrm{X}$ syndrome and fragile $\mathrm{X}$-associated disorders. fragile $\mathrm{X}$ syndrome and premutation disorders. In: Clinics in Developmental Medicine. Mac Keith press; 2020.

62. Cao Z, Hulsizer S, Cui Y, et al. Enhanced asynchronous $\mathrm{Ca}(2+)$ oscillations associated with impaired glutamate transport in cortical astrocytes expressing Fmr1 gene premutation expansion. $J$ Biol Chem. 2013;288(19):13831-13841. doi:10.1074/jbc.M112.441055

63. Wang JY, Ngo MM, Hessl D, et al. Robust machine learning-based correction on automatic segmentation of the cerebellum and brainstem. PLoS One. 2016;11(5):e0156123. doi:10.1371/journal.pone. 0156123

64. Todd PK, Oh S, Krans A, et al. CGG repeat-associated translation mediates neurodegeneration in fragile $\mathrm{X}$ tremor ataxia syndrome. Neuron. 2013;78(3):440-455. doi:10.1016/j.neuron.2013.03.026

65. Napoli E, Ross-Inta C, Song G, et al. Premutation in the fragile $\mathrm{X}$ mental retardation 1 (FMR1) gene affects maternal zn-milk and perinatal brain bioenergetics and scaffolding. Front Neurosci. 2016;10:159. doi:10.3389/fnins.2016.00159

66. Napoli E, Ross-Inta C, Wong S, et al. Altered zinc transport disrupts mitochondrial protein processing/import in fragile X-associated tremor/ataxia syndrome. Hum Mol Genet. 2011;20 (15):3079-3092. doi:10.1093/hmg/ddr211

67. Rogers H, Ariza J, Monterrubio A, et al. Cerebellar mild iron accumulation in a subset of FMR1 premutation carriers with FXTAS. Cerebellum. 2016;15(5):641-644. doi:10.1007/s12311016-0798-5

68. Ariza J, Steward C, Rueckert F, et al. Dysregulated iron metabolism in the choroid plexus in fragile X-associated tremor/ataxia syndrome. Brain Res. 2015;1598:88-96. doi:10.1016/j. brainres.2014.11.058

69. Ross-Inta C, Omanska-Klusek A, Wong S, et al. Evidence of mitochondrial dysfunction in fragile $\mathrm{X}$-associated tremor/ataxia syndrome. Biochem J. 2010;429(3):545-552. doi:10.1042/ BJ20091960

70. Ligsay A, El-Deeb M, Salcedo-Arellano MJ, et al. General anesthetic use in fragile X spectrum disorders. J Neurosurg Anesthesiol. 2019;31(3):285-290. doi:10.1097/ANA.0000000000000508

71. Muzar Z, Lozano R, Schneider A, et al. Methadone use in a male with the FMRI premutation and FXTAS. Am J Med Genet A. 2015;167(6):1354-1359. doi:10.1002/ajmg.a.37030

72. Muzar Z, Adams PE, Schneider A, et al. Addictive substances may induce a rapid neurological deterioration in fragile $\mathrm{X}$-associated tremor ataxia syndrome: a report of two cases. Intractable Rare Dis Res. 2014;3(4):162-165. doi:10.5582/ irdr.2014.01023

73. O'Dwyer JP, Clabby C, Crown J, et al. Fragile X-associated tremor/ataxia syndrome presenting in a woman after chemotherapy. Neurology. 2005;65(2):331-332. doi:10.1212/01. wnl.0000168865.36352.53

74. Paul R, Pessah IN, Gane L, et al. Early onset of neurological symptoms in fragile $\mathrm{X}$ premutation carriers exposed to neurotoxins. Neurotoxicology. 2010;31(4):399-402. doi:10.1016/ j.neuro.2010.04.002 
75. Allen EG, Sullivan AK, Marcus M, et al. Examination of reproductive aging milestones among women who carry the FMR1 premutation. Hum Reprod. 2007;22(8):2142-2152. doi:10.1093/ humrep/dem 148

76. López-Torres Hidalgo J. Effectiveness of physical exercise in the treatment of depression in older adults as an alternative to antidepressant drugs in primary care. BMC Psychiatr. 2019;19(1):21. doi:10.1186/s12888-018-1982-6

77. Bora E, Yücel M, Fornito A, et al. White matter microstructure in opiate addiction. Addict Biol. 2012;17(1):141-148. doi:10.1111/ j.1369-1600.2010.00266.x

78. El-Deeb M, Adams P, Schneider A, Salcedo-Arellano MJ, Tassone F, Hagerman R. Fentanyl overdose in a female with the FMR1 premutation and FXTAS. J Mol Genet (Isleworth). 2018;1(1):101.

79. Kogan CS, Turk J, Hagerman RJ, et al. Impact of the Fragile $\mathrm{X}$ mental retardation 1 (FMR1) gene premutation on neuropsychiatric functioning in adult males without fragile $\mathrm{X}$-associated Tremor/Ataxia syndrome: a controlled study. Am J Med Genet B Neuropsychiatr Genet. 2008;147b(6):859-872. doi:10.1002/ ajmg.b.30685

80. Dorn MB, Mazzocco MM, Hagerman RJ. Behavioral and psychiatric disorders in adult male carriers of fragile X. J Am Acad Child Adolesc Psychiatry. 1994;33(2):256-264. doi:10.1097/ 00004583-199402000-00015

81. Loesch DZ, Sherwell S, Kinsella G, et al. Fragile X-associated tremor/ataxia phenotype in a male carrier of unmethylated full mutation in the FMR1 gene. Clin Genet. 2012;82(1):88-92. doi:10.1111/j.1399-0004.2011.01675.x

82. Zahr NM, Kaufman KL, Harper CG. Clinical and pathological features of alcohol-related brain damage. Nat Rev Neurol. 2011;7 (5):284-294. doi:10.1038/nrneurol.2011.42

83. Mesa Suárez P, Santotoribio JD, Ramos Ramos V, et al. [Brain damage after general anesthesia]. Med Clin (Barc). 2016;146 (9):384-388. Portuguese. doi:10.1016/j.medcli.2016.01.018

84. Walker AE, Eskurza I, Pierce GL, et al. Modulation of vascular endothelial function by low-density lipoprotein cholesterol with aging: influence of habitual exercise. Am J Hypertens. 2009;22 (3):250-256. doi:10.1038/ajh.2008.353

85. Karssemeijer EGA, Aaronson JA (Justine), Bossers WJ (Willem), et al. Positive effects of combined cognitive and physical exercise training on cognitive function in older adults with mild cognitive impairment or dementia: a meta-analysis. Ageing Res Rev. 2017;40:75-83. doi:10.1016/j.arr.2017.09.003

86. Cassilhas RC, Tufik S, de Mello MT. Physical exercise, neuroplasticity, spatial learning and memory. Cell Mol Life Sci. 2016;73 (5):975-983. doi:10.1007/s00018-015-2102-0

87. Simkin DR, Black NB. Meditation and mindfulness in clinical practice. Child Adolesc Psychiatr Clin N Am. 2014;23 (3):487-534. doi:10.1016/j.chc.2014.03.002

88. Wielgosz J, Goldberg SB, Kral TRA, et al. Mindfulness meditation and psychopathology. Annu Rev Clin Psychol. 2019;15:285-316. doi:10.1146/annurev-clinpsy-021815-093423

89. Cherkin DC, Sherman KJ, Balderson BH, et al. Effect of mindfulness-based stress reduction vs cognitive behavioral therapy or usual care on back pain and functional limitations in adults with chronic low back pain: a randomized clinical trial. JAMA. 2016;315(12):1240-1249. doi:10.1001/jama.2016.2323

90. Turner JA, Anderson ML, Balderson BH, et al. Mindfulnessbased stress reduction and cognitive behavioral therapy for chronic low back pain: similar effects on mindfulness, catastrophizing, self-efficacy, and acceptance in a randomized controlled trial. Pain. 2016;157(11):2434-2444. doi:10.1097/j.pain.000 0000000000635
91. Hunter JE, Jenkins CL, Grim V, et al. Feasibility of an app-based mindfulness intervention among women with an FMR1 premutation experiencing maternal stress. Res Dev Disabil. 2019;89:76-82. doi:10.1016/j.ridd.2019.03.008

92. Schepici G, Bramanti P, Mazzon E. Efficacy of sulforaphane in neurodegenerative diseases. Int J Mol Sci. 2020;21(22):8637. doi:10.3390/ijms21228637

93. Abrahams S, Haylett WL, Johnson G, et al. Antioxidant effects of curcumin in models of neurodegeneration, aging, oxidative and nitrosative stress: a review. Neuroscience. 2019;406:1-21. doi:10.1016/j.neuroscience.2019.02.020

94. Napoli E, Flores A, Mansuri Y, Hagerman RJ, Giulivi C. Sulforaphane improves mitochondrial metabolism in fibroblasts from patients with fragile $\mathrm{X}$-associated tremor and ataxia syndrome. Neurobiol Dis. 2021;157:105427. doi:10.1016/j.nbd.2021.105427

95. Jo A, Lee Y, Kam TI, et al. Paris farnesylation prevents neurodegeneration in models of Parkinson's disease. Sci Transl Med. 2021;13(604). doi:10.1126/scitranslmed.aax8891

96. Altimiras F, Garcia JA, Palacios-García I, et al. Altered gut microbiota in a fragile $\mathrm{X}$ syndrome mouse model. Front Neurosci. 2021;15:653120. doi:10.3389/fnins.2021.653120

97. Levkovich T, Poutahidis T, Smillie C, et al. Probiotic bacteria induce a 'glow of health'. PLoS One. 2013;8(1):e53867. doi:10.1371/journal.pone.0053867

98. Mohd Zaffarin AS, Ng S-F, Ng MH, et al. Pharmacology and pharmacokinetics of vitamin E: nanoformulations to enhance bioavailability. Int $J$ Nanomedicine. 2020;15:9961-9974. doi:10.2147/IJN.S276355

99. Grundman M. Vitamin E and Alzheimer disease: the basis for additional clinical trials. Am J Clin Nutr. 2000;71(2):630s-636s. doi:10.1093/ajen/71.2.630s

100. Crouzin N, de Jesus Ferreira M-C, Cohen-Solal C, et al. Neuroprotection induced by vitamin $\mathrm{E}$ against oxidative stress in hippocampal neurons: involvement of TRPV1 channels. Mol Nutr Food Res. 2010;54(4):496-505. doi:10.1002/ mnfr.200900188

101. Hagerman RJ, Jackson AW, Levitas A, et al. Oral folic acid versus placebo in the treatment of males with the fragile $\mathrm{X}$ syndrome. Am J Med Genet. 1986;23(1-2):241-262. doi:10.1002/ajmg.1320230119

102. Schneider JA, Tangney CC, Morris MC. Folic acid and cognition in older persons. Expert Opin Drug Saf. 2006;5(4):511-522. doi:10.1517/14740338.5.4.511

103. Reiter RJ, Mayo JC, Tan DX, Sainz RM, Alatorre-Jimenez M, Qin L. Melatonin as an antioxidant: under promises but over delivers. J Pineal Res. 2016;61(3):253-278.

104. Zisapel N. New perspectives on the role of melatonin in human sleep, circadian rhythms and their regulation. Br J Pharmacol. 2018;175(16):3190-3199. doi:10.1111/bph.14116

105. Tamura H, Jozaki M, Tanabe M, et al. Importance of melatonin in assisted reproductive technology and ovarian aging. Int J Mol Sci. 2020;21(3):1135. doi:10.3390/ijms21031135

106. Raizner AE. Coenzyme Q(10). Methodist Debakey Cardiovasc J. 2019;15(3):185-191. doi:10.14797/mdcj-15-3-185

107. Wang Y, Hekimi S. Understanding ubiquinone. Trends Cell Biol. 2016;26(5):367-378. doi:10.1016/j.tcb.2015.12.007

108. Manzar H, Abdulhussein D, Yap TE, et al. Cellular consequences of coenzyme Q10 deficiency in neurodegeneration of the retina and brain. Int J Mol Sci. 2020;21(23):9299. doi:10.3390/ ijms21239299

109. Jelinek A, Heyder L, Daude M, et al. Mitochondrial rescue prevents glutathione peroxidase-dependent ferroptosis. Free Radic Biol Med. 2018;117:45-57. doi:10.1016/j.freeradbiomed.2018.01.019 
110. Small GW, Siddarth P, Li Z, et al. Memory and brain amyloid and tau effects of a bioavailable form of curcumin in non-demented adults: a double-blind, placebo-controlled 18-month trial. Am $J$ Geriatr Psychiatry. 2018;26(3):266-277. doi:10.1016/j. jagp.2017.10.010

111. Di Meo F, Margarucci S, Galderisi U, Crispi S, Peluso G. Curcumin, gut microbiota, and neuroprotection. Nutrients. 2019;11(10):2426. doi:10.3390/nu11102426

112. Kiefer D, Pantuso T. Panax ginseng. Am Fam Physician. 2003;68 (8):1539-1542.

113. DiNicolantonio JJ, O'Keefe JH. The importance of marine omega-3s for brain development and the prevention and treatment of behavior, mood, and other brain disorders. Nutrients. 2020;12 (8):2333. doi:10.3390/nu12082333

114. Ohishi T, Goto S, Monira P, et al. Anti-inflammatory action of green tea. Antiinflamm Antiallergy Agents Med Chem. 2016;15 (2):74-90. doi:10.2174/1871523015666160915154443

115. Chu C, Deng J, Man Y, et al. Green tea extracts epigallocatechin-3-gallate for different treatments. Biomed Res Int. 2017;2017:5615647. doi:10.1155/2017/5615647

116. Chakrawarti L, Agrawal R, Dang S, et al. Therapeutic effects of EGCG: a patent review. Expert Opin Ther Pat. 2016;26 (8):907-916. doi:10.1080/13543776.2016.1203419

117. Mattioli R, Francioso A, Mosca L, et al. Anthocyanins: a comprehensive review of their chemical properties and health effects on cardiovascular and neurodegenerative diseases. Molecules. 2020;25(17):3809. doi:10.3390/molecules25173809

118. Azzini E, Giacometti J, Russo GL. Antiobesity effects of anthocyanins in preclinical and clinical studies. Oxid Med Cell Longev. 2017;2017:2740364. doi:10.1155/2017/2740364

119. Garg G, Singh S, Singh AK, et al. N-acetyl-1-cysteine attenuates oxidative damage and neurodegeneration in rat brain during aging. Can J Physiol Pharmacol. 2018;96(12):1189-1196. doi:10.1139/cjpp-2018-0209

120. Gantois I, Popic J, Khoutorsky A, et al. Metformin for treatment of fragile X syndrome and other neurological disorders. Annu Rev Med. 2019;70:167-181. doi:10.1146/annurev-med-081117-041238

121. Romero R, Erez O, Hüttemann M, et al. Metformin, the aspirin of the 21st century: its role in gestational diabetes mellitus, prevention of preeclampsia and cancer, and the promotion of longevity. Am J Obstet Gynecol. 2017;217(3):282-302.

122. Dy ABC, Tassone F, Eldeeb M, Salcedo-Arellano MJ, Tartaglia N, Hagerman R. Metformin as targeted treatment in fragile X syndrome. Clin Genet. 2018;93(2):216-222.
123. Kim J, Choi JY, Seo J, Choi IS. Neuroprotective effect of cannabidiol against hydrogen peroxide in hippocampal neuron culture. Cannabis Cannabinoid Res. 2021;6(1):40-47.

124. Sagredo O, Ruth Pazos M, Valdeolivas S, et al. Cannabinoids: novel medicines for the treatment of Huntington's disease. Recent Pat CNS Drug Discov. 2012;7(1):41-48. doi:10.2174/ 157488912798842278

125. Heussler H, Cohen J, Silove N, et al. A phase $1 / 2$, open-label assessment of the safety, tolerability, and efficacy of transdermal cannabidiol (ZYN002) for the treatment of pediatric fragile $\mathrm{X}$ syndrome. J Neurodev Disord. 2019;11(1):16. doi:10.1186/ s11689-019-9277-x

126. Blessing EM, Steenkamp MM, Manzanares J, et al. Cannabidiol as a potential treatment for anxiety disorders. Neurotherapeutics. 2015;12(4):825-836. doi:10.1007/s13311-015-0387-1

127. Hampel H, Williams $\mathrm{C}$, Etcheto A, et al. A precision medicine framework using artificial intelligence for the identification and confirmation of genomic biomarkers of response to an Alzheimer's disease therapy: analysis of the blarcamesine (ANAVEX2-73) phase 2a clinical study. Alzheimers Dement (N Y). 2020;6(1):e12013.

128. Samantha TR. HDAC2 targeting stabilizes the CoREST complex in renal tubular cells and protects against renal ischemia/reperfusion injury. Sci Rep. 2021;11:1-3.

129. Aufhauser DD, Hernandez P, Concors SJ, et al.. The molecular function of $\sigma$ receptors: past, present, and future. Trends Pharmacol Sci. 2019;40(9):636-654. doi:10.1016/j. tips.2019.07.006

130. Ryskamp DA, Korban S, Zhemkov V, et al. Neuronal sigma-1 receptors: signaling functions and protective roles in neurodegenerative diseases. Front Neurosci. 2019;13(862). doi:10.3389/ fnins.2019.00862

131. Kaufmann WE, Sprouse J, Rebowe N, et al. ANAVEX ${ }^{\circledR} 2-73$ (blarcamesine), a Sigma-1 receptor agonist, ameliorates neurologic impairments in a mouse model of Rett syndrome. Pharmacol Biochem Behav. 2019;187:172796. doi:10.1016/j.pbb.20 19.172796

132. Reyes ST, Deacon RMJ, Guo SG, et al. Effects of the sigma-1 receptor agonist blarcamesine in a murine model of fragile $\mathrm{X}$ syndrome: neurobehavioral phenotypes and receptor occupancy. Sci Rep. 2021;11(1):17150. doi:10.1038/s41598-02194079-7

\section{Publish your work in this journal}

Pharmacogenomics and Personalized Medicine is an international, peer-reviewed, open access journal characterizing the influence of genotype on pharmacology leading to the development of personalized treatment programs and individualized drug selection for improved safety, efficacy and sustainability. This journal is indexed on the American Chemical Society's Chemical Abstracts Service (CAS). The manuscript management system is completely online and includes a very quick and fair peer-review system, which is all easy to use. Visit http://www.dovepress.com/testimonials.php to read real quotes from published authors. 